Mycologia, 103(4), 2011, pp. 904-911. DOI: 10.3852/10-382

(C) 2011 by The Mycological Society of America, Lawrence, KS 66044-8897

\title{
A new annulate Pluteus variety from Italy
}

\author{
Alfredo Vizzini ${ }^{1}$ \\ Enrico Ercole \\ Dipartimento di Biologia Vegetale, Università di \\ Torino, Viale Mattioli 25, Torino 10125, Italy
}

\begin{abstract}
Pluteus aurantiorugosus, var. aurantiovelatus var. nov., is described from Italy based on both morphological and ITS rDNA data. This taxon is characterized by an ornamented stipe provided with reddish orange remnants of a partial veil. The occurrence of the partial veil in Pluteus also is discussed.
\end{abstract}

Key words: Agaricales, Basidiomycota, Chamaeota, Pluteaceae, Pluteus sect. Celluloderma, taxonomy

\section{INTRODUCTION}

Pluteus, typified by P. cervinus (Schaeff.) P. Kumm., traditionally encompasses saprobic agarics with free gills, a usually gymnocarpic development, pinkish spore-print, inverse hymenophoral trama and inamyloid spores (Singer 1986). It includes approximately 300 species and is widely distributed (Kirk et al. 2008). Its infrageneric taxonomy is based primarily on the characteristics of hymenial cystidia and pileipellis. Three sections based on morphological features are widely accepted in Pluteus (Singer 1986, Malysheva et al. 2009, Minnis and Sundberg 2010): sect. Pluteus, having thick-walled (metuloid) and usually apically digitated pleurocystidia and a cutis as pileipellis; sect. Hispidoderma Fayod, having non-metuloid pleurocystidia and a pileipellis consisting of elongated elements organized either as a cutis, a hymeniderm or a trichoderm; sect. Celluloderma Fayod, having nonmetuloid pleurocystidia and a pileipellis composed of swollen clavate or spheropedunculate elements organized in a hymeniderm, with transitions to an epithelium. Singer (1956, 1958, 1986) also considered two subsections in section Celluloderma: Mixtini Singer and Eucellulodermini Singer, differing respectively by the presence or absence of elongated cystidium-like elements in the pileipellis. Finally, Vellinga and Schreurs (1985) proposed an infrageneric classification for Pluteus only slightly diverging from Singer's classificatory scheme.

Papers by Justo et al. (2011a, b) showed a general agreement between morphological subdivision of

Submitted 29 Nov 2010; accepted for publication 27 Jan 2011.

${ }^{1}$ Corresponding author. E-mail: alfredo.vizzini@unito.it
Pluteus and the molecular phylogeny, even if (i) some species with non-metuloid pleurocystidia and pileipellis as a cutis are placed either in sect. Celluloderma, together with the species characterized by a hymenidermal pileipellis, or in sect. Pluteus with metuloid bearing species; (ii) the division of sect. Celluloderma into subsect. Mixtini Singer and subsect. Eucellulodermini is not supported by the phylogenetic analyses of the molecular data.

Regarding developmental data, preliminary studies on basidiome morphogenesis of agaricoid fungi (Walker 1919, Reijnders 1963, Gorovoj 1990) have highlighted that a few Pluteus species can display an inconspicuous, strongly reduced and fugacious appendiculate-cortinoid partial veil due to a nongymnocarpic development. In particular $P$. chrysophlebius (Berk. \& M.A. Curtis) Sacc. var. chrysophlebius of sect. Celluloderma is characterized by a slightly pilangiocarpic or stipitangiocarpic development (Walker 1919 and Reijnders 1963 as P. admirabilis; Gorovoj 1990); P. romellii (Britzelm.) Sacc. of sect. Celluloderma sometimes by a reduced paravelangiocarpic development (Reijnders 1963 as P. lutescens [Fr.] Bres.); P. granulatus Bres. of sect. Hispidoderma by a paravelangiocarpic development (Reijnders 1963). Singer (1958) also has described from South America two Pluteus species with rudimental volva-like remnants ( $P$. circumscissus Singer of sect. Hispidoderma and $P$. stephanobasis Singer of sect. Pluteus).

Minnis et al. (2006) and Corriol and Moreau (2007) transferred two annulate species formerly placed in genus Chamaeota (W.G. Sm.) Earle to Pluteus based on molecular and morphological evidence (Minnis et al. 2006, Corriol and Moreau 2007, Malysheva et al. 2007, Minnis and Sundberg 2009).

During fieldwork in a hilly park near Torino (Piedmont, Italy) we collected a striking Pluteus with a yellow stipe, an orange-red pileus and a stipe ornamented by an orange partial veil. Based on both morphological features and ITS rDNA analyses, the taxon here is described as a new variety of $P$. aurantiorugosus (Trog) Sacc.

\section{MATERIALS AND METHODS}

Morphology.-The micromorphological descriptions are based on study of herbarium material. We observed microscopic characters on dried material rehydrated in $3 \% \mathrm{KOH}$ and stained in Congo red, cresyl blue and Melzer's reagent separately. Spore dimensions are based on mea- 
surements of 40 spores stained in Melzer's reagent. The width of each basidium was measured at the widest part, and the length was measured from the apex (sterigmata excluded) to the basal septum. These abbreviations are used: $Q=$ the quotient of length and width of the spores in side view, $\mathrm{Qm}=$ average quotient, $\mathrm{L}=$ number of lamellae, $1=$ number of lamellulae between each pair of lamellae.

Color comparisons were made with the Methuen Handbook of Color (Kornerup and Wanscher 1978) and designated (4A6-7), which indicates plate, row and color blocks. Author citations follow the Index Fungorum Authors of Fungal Names (http://www.indexfungorum. org/authorsoffungalnames.htm). Herbarium abbreviations are according to Thiers (2010). The Latin description of the new taxon is deposited in MycoBank (http://www. mycobank.org/DefaultPage.aspx).

DNA extraction, PCR amplification and DNA sequencing.Genomic DNA was isolated from $1 \mathrm{mg}$ dried herbarium specimen from two collections (TO AVPP211 and TO AVPP212), with the DNeasy Plant Mini Kit (QIAGEN, Milan, Italy) according to manufacturer's instructions. Universal primers ITS1F/ITS4 were used for the ITS region amplification (White et al. 1990, Gardes and Bruns 1993). Amplification reactions were performed in a PE9700 thermal cycler (Perkin-Elmer, Applied Biosystems) following Vizzini et al. (2011). PCR products were purified with the AMPure XP kit (Beckman) and sequenced by DiNamyCode srl (Torino, Italy). The sequences were assembled and edited with the phred/phrap/consed software suite. The sequences were submitted to GenBank (http://www.ncbi. nlm.nih.gov/genbank/), and their accession numbers are reported under Material studied); the alignments and phylogenetic tree are available at TreeBASE (www. treebase.org) under accession number S11061.

Sequence alignment and phylogenetic analysis.-The sequences obtained in this study were checked and assembled with Geneious 5.1.6 (Drummond et al. 2009) and compared to those available in the GenBank database (http://www. ncbi.nlm.nih.gov/Genbank/) with the BLASTN algorithm. Based on the BLASTN results, sequences were selected according to the outcomes of recent phylogenetic studies on Pluteus (Justo et al. 2011a, b; Menolli et al. 2010). Four Pluteus species belonging to sect. Pluteus (P. albostipitatus [FJ816656], P. pellitus [HM562036], P. pouzarianus [HM562154] and P. cervinus [HM562165]) were used as outgroup taxa. The alignment was generated for the ITS dataset with Clustal X 2.0 (Larkin et al. 2007) with default conditions for gap openings and gap extension penalties. The alignment was imported into MEGA 4.0 (Tamura et al. 2007) for manual adjustment. The best-fit models were estimated by both the Akaike information criterion (AIC) and the Bayesian information criterion (BIC) with jModelTest 0.1.1 (Posada 2008) to provide a substitution model for the alignment. We chose the HKY + G substitution model for the analyses.

Phylogenetic analyses were performed with Bayesian inference (BI) and maximum parsimony (MP). BI of phylogeny with Monte Carlo Markov chains (MCMC) was carried out with MrBayes 3.1.2 (Huelsenbeck and Ronquist
2001). Four incrementally heated simultaneous MCMC were run over 10000000 generations. Trees were sampled every 1000 generations, resulting in an overall sampling of 10001 trees. The first 2500 trees (25\%) were discarded as burn-in. For the remaining trees a majority rule consensus tree showing all compatible partitions was computed to obtain estimates for Bayesian posterior probabilities (BPP). Branch lengths were estimated as mean values over the sampled trees. Only BPP values exceeding $50 \%$ are reported in the resulting trees. This Bayesian analysis was repeated three times, always using random starting trees and random starting values for model parameters to test the independence of results from revisiting of prior topologies during chain growth (Huelsenbeck et al. 2002).

MP analysis was performed with PAUP* 4.0b10 (Swofford 2002) with the heuristic search mode with 100 random addition sequence replicates and tree bisection reconnection (TBR) branch swapping but keeping only 10 trees per replicate to discover possible islands of maximum parsimony. All character states were treated as unordered and equally weighted. Gaps were treated as missing data. Branch robustness was estimated by nonparametric bootstrapping (Felsenstein 1985) with 500 replicates with 10 random addition replicates per bootstrap. Only bootstrap values exceeding $50 \%$ are shown in the resulting tree. Support values for major clades that are supported in both BI and MP are shown in the resulting tree. Analysis of the pairwise percent identity for the treated $P$. aurantiorugosus sequences was calculated with MEGA 4.0 (Tamura et al. 2007).

\section{RESULTS}

Molecular analyses. - The amplification of the ITS regions was successful for the two specimens, yielding a PCR product of ca. $615 \mathrm{bp}$. The ITS data matrix comprises a total of 25 sequences (including 23 from GenBank). This dataset is 641 base pairs long and contains $309(48.2 \%)$ variable sites. Of these 243 $(37.9 \%)$ are parsimony informative.

The topologies of the BI and MP trees are congruent, and both analyses have reported high support values for most branches (FIG. 3). The two Pluteus aurantiorugosus var. aurantiovelatus sequences clustered with five $P$. aurantiorugosus var. aurantiorugosus sequences forming a clade with $100 \%$ branch support in both MP and BI trees. This clade is composed of seven $P$. aurantiorugosus sequences, three from North America, two from Italy, one from Spain and one from Japan and is sister to the clade consisting of $P$. romellii sequences. The pairwise percent identity of the entire $P$. aurantiorugosus clade is $99.4 \%$.

\section{TAXONOMY}

Pluteus aurantiorugosus var. aurantiovelatus Vizzini, var. nov. Figs. 1, 2 MycoBank MB 519602 

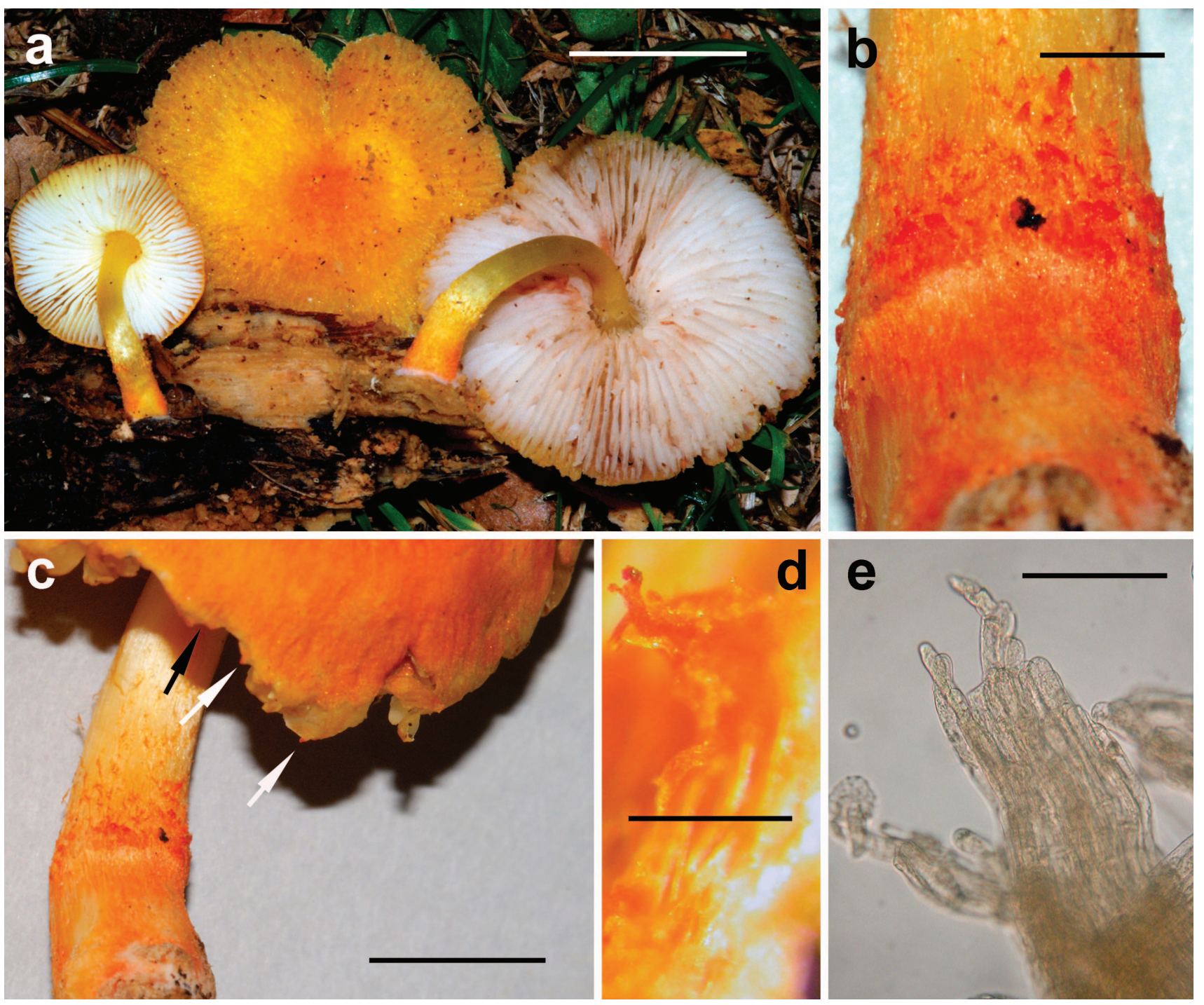

FIG. 1. Pluteus aurantiorugosus var. aurantiovelatus. a. Basidiomes (from holotype). b. Velar floccules on stipe. c. Velar floccules on stipe surface and pileus margin (arrows). d. Velar floccule on pileus margin. e. Hyphal bundle of the velum (from pileus margin). Bars: $\mathrm{a}=10 \mathrm{~mm}, \mathrm{~b}=1 \mathrm{~mm}, \mathrm{c}=5 \mathrm{~mm}, \mathrm{~d}=0.3 \mathrm{~mm}, \mathrm{e}=50 \mu \mathrm{m}$.

A typo differt stipite velo basali aurantio-fulvo ornato.

Typus. Italia, Piemonte, prov. Torino, ad locum dicto Valle Sappone, 10/10/2010, leg. G. Buffa (TO AVPP212, holotypus).

Etymology. the specific epithet, derived from the Latin words aurantiacus (orange) and velatus (with veil), refers to the orange-red veil decorating the stipe and pileus margin.

Pileus 10-22 mm diam, conical to convex, umbonate, with an obtuse and flat umbo, at first deep orange-red (7A7-8), then orange (5A7-8; 6A7-8), and fading to deep yellow (4A6-7-8); surface slightly hygrophanous, smooth to minutely granular to rimose, finely appressed-fibrillose toward the margin, veinedrugulose at center; margin slightly sulcate, translucently striate and eroded, often with fugacious orange floccules of partial veil (FIG. 1c, d). Lamellae L $=45-$ $60,1=1-3(4)$, free, up to 3-4 mm broad, whitish, bruising yellow, then pale pink to orange-pink (6A3) due to spore maturation, with flocculose white edges. Stipe $15-40 \times 2-4 \mathrm{~mm}$, straight to curved, cylindrical or slightly broadened at base, base clavate or globose, often slightly marginate, surface shiny, fibrillose to striate, yellow (4A6-7-8), with a fine ring zone delimited by easily removable orange-red (5A8; 4A67) floccules in the lower part (it looks like the velar remnants on the stipe of Coprinopsis atramentaria species complex); mycelium at base white. Context whitish in the pileus, yellowish in stipe. Odor and flavor indistinct. Spore print pale pinkish.

Spores (4.9)6.0-6.6(7.6) $\times(3.3) 3.5-4.7(4.9) \mu \mathrm{m}$, $6.47 \times 4.33 \mu \mathrm{m}$ on average, $\mathrm{Q}=(1.22) 1.3-1.71(1.82)$, 

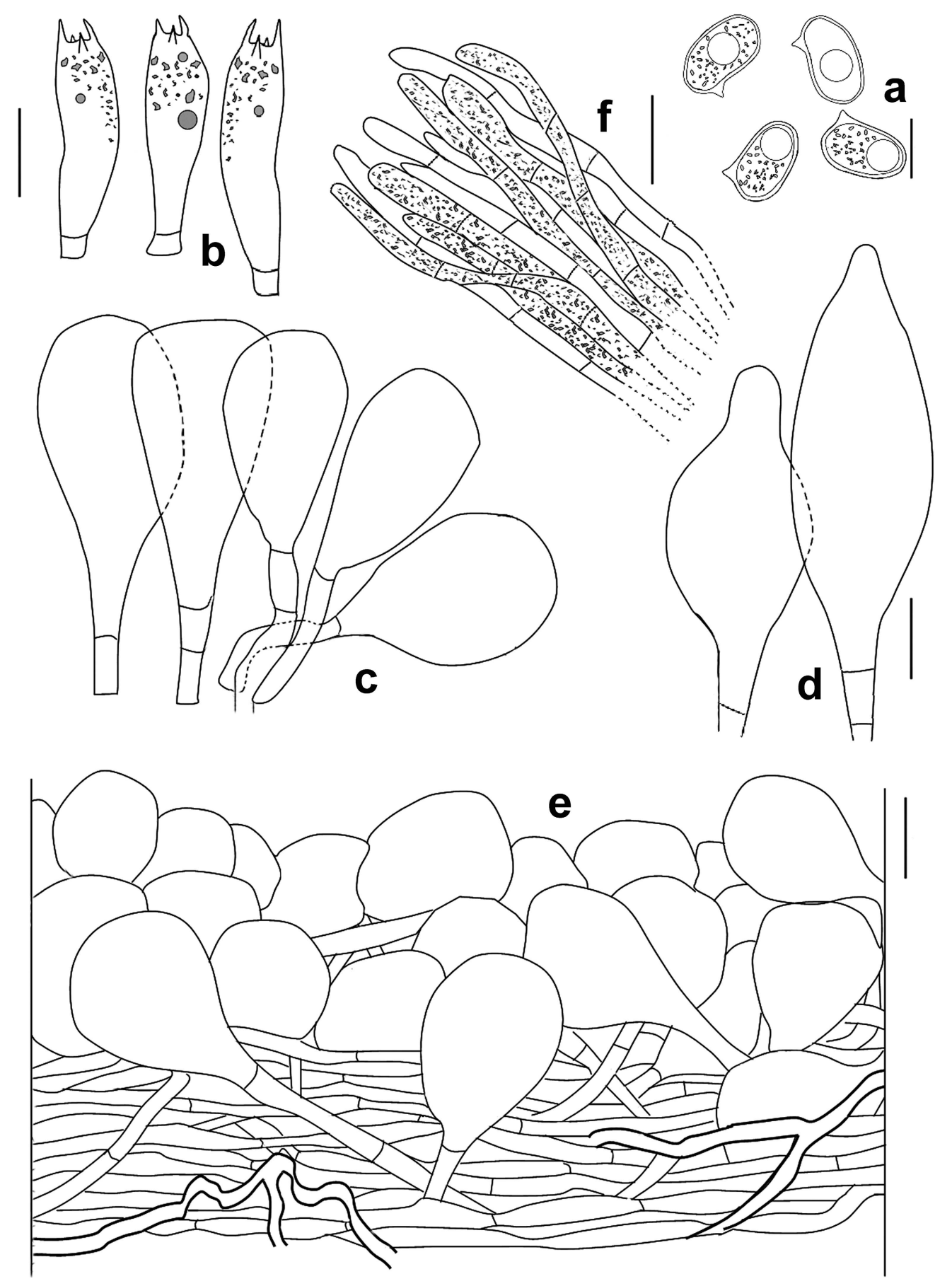

FIG. 2. Pluteus aurantiorugosus var. aurantiovelatus. Microscopic features. a. Spores. b. Basidia. c. Cheilocystidia. d. Pleurocystidia. e. Pileipellis. f. Elements of the veil. Bars: $\mathrm{a}=5 \mu \mathrm{m} ; \mathrm{b}, \mathrm{c}, \mathrm{d}=10 \mu \mathrm{m}$; $\mathrm{e}=30 \mu \mathrm{m}$; $\mathrm{f}=20 \mu \mathrm{m}$.

$\mathrm{Qm}=1.46$, ellipsoid, smooth; walls slightly thickened; subhyaline to pale yellow in $\mathrm{KOH}$, with a single large oil drop inside or several smaller drops resulting in a granular appearance (FIG. 2a). Basidia clavate, tetraspored, 25-30 $\times 6-8 \mu \mathrm{m}$, thin-walled and hyaline in KOH (FIG. 2b). Cheilocystidia abundant, vesiculose to clavate, pyriform, 35-45 $\times 12.5-22.5 \mu \mathrm{m}$, thinwalled and hyaline in $\mathrm{KOH}$, septate at the base
(FIG. 2c). Pleurocystidia scattered, moderately abundant, broadly to narrowly fusoid-ventricose with pedicels and short necks with obtuse apices, thinwalled, 40-55(60) $\times$ 20-23 $\mu \mathrm{m}$, hyaline in $\mathrm{KOH}$ (FIG. 2d). Hymenophoral trama inversely bilateral with convergent hyphae, 2-18 $\mu \mathrm{m}$ diam, thin-walled, hyaline, septate. Pileipellis (FIG. 2e) made up of a suprapellis consisting of a hymeniderm-epithelium of 
clavate, vesiculose, pyriform, sphaeropedunculate elements, 27.5-55 $\mu \mathrm{m}$ wide, thin-walled with pale yellowish cytoplasmatic contents, or colorless; subpellis made up of cylindrical, 4-6 $\mu \mathrm{m}$ wide hyphae, without pigments. Stipe trama consisting of parallel, 4-16 $\mu \mathrm{m}$ diam, thin-walled, hyaline hyphae. Veil floccules in form of bundles of densely septate hyphae (FIG. 2f), 15-50(70) $\times$ (5)6.3-9.5 $\mu \mathrm{m}$, with abundant orange cytoplasmatic pigmentation, running perpendicular to pileus and stipe surface and independent from that. Caulocystidia and clamp connections absent. Thromboplerous hyphae abundant in subpellis and stipe trama.

Habitat. In a basal cleft of the stem of a living Populus $\mathrm{x}$ canadensis.

Specimens examined. ITALY: Piedmont, Torino, Valle Sappone, along Sappone River, 260 m, leg. G. Buffa, 4 Oct 2010 (TO AVPP211, GenBank HQ654907); ibidem, leg. G. Buffa, 10 Oct 2010 (TO AVPP212, GenBank HQ654908, holotypus).

Additional specimens examined. P. aurantiorugosus var. aurantiorugosus: ITALY: Piedmont, Torino, Colle della Maddalena, $400 \mathrm{~m}$, on Populus sp. log, leg. A. Vizzini, 12 Sep 1992 (TO AVPP04); Piedmont, Venaria Reale, Parco "La Mandria", 260 m, on Quercus rubra log, leg. G. Moretto, 11 Oct 2009 (TO AVPP38). P. fenzlii: FRANCE: Ariège. Montseron, Roquebrune, on Hedera helix, $400 \mathrm{~m}$, leg. J. Fournier, 15 Sep 1998, det. G. Corriol, herb. J. Fournier 98145 (LIP), cited in Corriol and Moreau (1997).

\section{DISCUSSION}

P. aurantiorugosus var. aurantiovelatus is characterized by a "booted" stipe, where the partial veil's point of attachment to the stipe is at its base and the entire stipe (below the point of the annulus) ends up covered with fragments of partial veil. The presence of this persistent veil on stipe and pileus margin is the main feature separating this new variety from all collections and reports of Pluteus aurantiorugosus (Trog.) Sacc. (sect. Celluloderma, subsect. Eucellulodermini) in which the basidiome is unveiled (Homola 1972, Orton 1986, Bon 1987, Dermek 1987, Vellinga 1990, Courtecuisse and Duhem 1994, Citerin and Eyssartier 1998, Consiglio 2000, Heilmann-Clausen 2008, Minnis and Sundberg 2010). In particular the stipe of $P$. aurantiorugosus var. aurantiorugosus has been described as "fibrillose to fibrillose-scaly when young, at maturity fibrillose only towards base..." (Homola 1972); " sometimes tinged orange or scarlet at base or from base up, silky-fibrillose striate, sometimes silky floccose when young" (Orton 1986); "golden towards the base" (Bon 1987); "innately fibrillose-striate" (Vellinga 1990); "blanc à base jaune" (Courtecuisse and Duhem 1994); "darker yellow towards base, lengthwise striate, smooth"
(Heilmann-Clausen 2008); “surface shiny, fibrillosestriate above, fibrillose and subscaly below" (Minnis and Sundberg 2010). These authors never found velar floccules on the stipe surface or the pileus margin, but in some collections only scattered colorless fibrils restricted to the stipe base were described, hardly referable to veil remnants. In two $P$. aurantiorugosus var. aurantiorugosus collections housed at TO (three young basidiomes, TO AVPP04 and TO AVPP38) we found no velar remnants at all but only a translucently striate stipe.

Secondary distinguishing features of the new variety with respect to the typical variety include the striate pileus margin and the spores only 3.5-4.7(4.9) $\mu \mathrm{m}$ wide. In $P$. aurantiorugosus var. aurantiorugosus spores seem slightly wider $(\times 4.5-5 \mu \mathrm{m}$, Homola $1972 ; \times 4.5-5 \mu \mathrm{m}$, Orton 1986; $\times[3.5] 4.0-5.5[6] \mu \mathrm{m}$, Vellinga 1990; $\times[3.5] 4-5.5[6] \mu \mathrm{m}$, Heilmann-Clausen 2008; $\times$ 4.4-6.2 $\mu \mathrm{m}$, Minnis and Sundberg 2010; $\times$ [3.5]4-5.5[6] $\mu \mathrm{m}$, Vizzini, collection TO AVPP04).

Among the veiled species of Pluteus, P. fenzlii (Schulzer) Corriol \& P.-A. Moreau from Europe, Asian Russia and Japan (Corriol and Moreau 2007, Malysheva et al. 2007, Justo et al. 2011b) and $P$. mammillatus (Longyear) Minnis, Sundb. \& Methven from North America (Minnis et al. 2006) differ in having a yellow pileus (without orange-red tinges), a pileipellis consisting entirely of elongated elements and an evident ring-like zone. In $P$. fenzlii the velum is formed by hyphal bundles with non-catenulate, up to $150 \mu \mathrm{m}$ long hyphae (Corriol and Moreau [2007], Moreau pers com, our observations on collection J. Fournier 98145 [LIP]), in $P$. aurantiorugosus var. aurantiovelatus the veil consists of short catenulate hyphae (up to $70 \mu \mathrm{m}$ long), and it can be assumed that such a veil cannot be very resistant and necessarily breaks into patches or flocks (as is the case in many Lepiota [Pers.] Gray species or Cystoderma Fayod). Chamaeota xanthogramma (Ces.) Earle, the type species of Chameota, is known only from Cesati's plate accompanying the original description (Cesati 1861), and its true identity has been questioned; it is actually considered "nomen dubium' by Corriol and Moreau (2007). Chamaeota tropica Pegler and C. subolivascens Courtec. are described as having a hymenidermal pileipellis (Pegler 1983, Courtecuisse 1991) but differ from $P$. aurantiorugosus var. aurantiovelatus in a pileus without yellow-orange tinges and deviating microscopic characters. Chamaeota dextrinoidespora Z.S. Bi (Bi and Li 1988) and C. sinica J.Z. Ying (Ying 1995), described from China, are in fact species of Leucoagaricus Locq. ex Singer (Yang 2007).

In regard to other non-veiled species of Pluteus belonging to sect. Celluloderma and with yellow- 


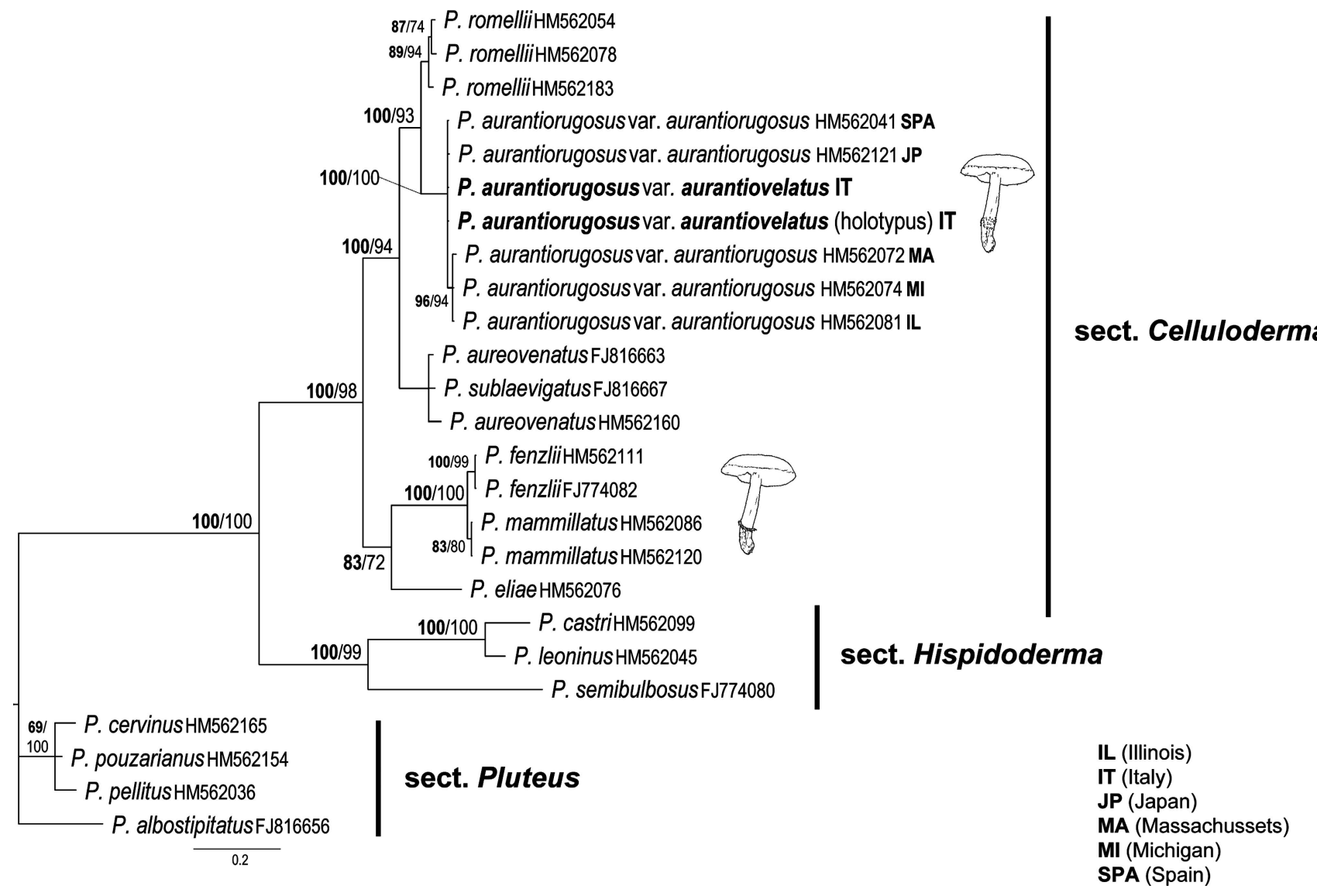

FIG. 3. Bayesian phylogram obtained from the ITS (ITS1-5.8S-ITS2) sequence alignment of Pluteus spp. P. albostipitatus, P. pellitus, $P$. pouzarianus and $P$. cervinus were used as outgroup taxa. The HKY $+\mathrm{G}$ substitution model was used in the Bayesian analysis. Support values for major clades that are supported in both the Bayesian (posterior probabilities percentage [BPP] in boldface) and maximum parsimony (MP bootstrap percentage, MPB analyses) are indicated. BPP/MPB exceeding $50 \%$ are given above branches. Bar indicates number of substitutions per site. Mushroom illustrations indicate veiled taxa. Sectional classification follows Justo et al. (2011a, b).

orange tinges, P. flammipes E. Horak (Horak 1964) and $P$. laetus Singer (Singer 1958, 1961) are characterized by a celluloderm-like pileipellis with cystidioid elements and the latter also by rostrate cheilocystidia. P. aureovenatus Menolli \& Capelari from Brazil (Menolli et al. 2010) is characterized by a deep yellowish orange and strongly veined pileus, translucently striate margin, sub-free and yellow lamellae, globose basidiospores $(6.2(-7.5) \times(5.0-)$ $6.2(-7.5) \mu \mathrm{m})$, and large non-pedicellate pileipellis elements. P. chrysophlebius (Berk. \& M.A. Curtis) Sacc. var. chrysophlebius $(=P$. aurantiacus Murrill, $=P$. admirabilis [Peck] Peck, fide Minnis and Sundberg 2010), P. laetifrons and its varieties (Dennis 1953, Singer 1958) and Pluteus nevadensis RodríguezAlcántar (Rodríguez et al. 2010), all have subglobose to broadly ellipsoid spores. Finally $P$. horakianus Rodríguez-Alcántar (Rodríguez et al. 2009) is distinguished by orange reddish lamellar edges and a red stipe.
It is evident from our ITS analyses (FIG. 3) that $P$. aurantiorugosus var. aurantiovelatus is not phylogenetically related to the other sequenced annulate taxa (viz. P. fenzlii and P. mammillatus), which implies that independent origins of partial veil acquisition or loss have taken place during the evolutionary history of Pluteus and also that this character is homoplasic and unsuitable for a natural classification of these fungi at the supraspecific rank, as stated by Singer (1958), Minnis and Sundberg (2009) and Justo et al. (2011a, b).

It is conceivable that the shift from a veiled to a non-veiled basidiome and vice versa in a single Pluteus species is under the control of a limited number of genes that can be inactivated readily and irreversibly by (so far unknown) environmental factors. In addition, as highlighted by recent molecular work (Peintner et al. 2001), mutations conferring the loss of functional development may occur in only a few genes therefore morphological reduction appears to 
be rapid relative to molecular changes (e.g. recessive alleles at a single locus can cause transitions from agaricoid to secotioid forms) (Hibbett et al. 1994).

We suggest that field collectors take care to note traces of partial veil on primordial basidiomes of Pluteus because it would increase the number of species with well developed veil currently placed in Pluteus.

\section{ACKNOWLEDGMENTS}

We thank L. Panno (University of Turin, Italy) for his helpful technical assistance and P.A. Moreau (Université Lille 2, France) for providing a P. fenzlii collection and observations on its velar structure.

\section{LITERATURE CITED}

Bi ZS, Li TH. 1988. Two new species of agarics from North Guangdon province of China. Bull Bot Res, Harbin 8(1):98-99.

Bon M. 1987. The mushrooms and toadstools of Britain and northwestern Europe. London: Hodder \& Stoughton. $352 \mathrm{p}$.

Cesati V. 1861. Appunti per una futura Crittogamologia Insubrica. Comment Soc Crittog Ital 2:47-72.

Citerin M, Eyssartier G. 1998. Clé analytique du genre Pluteus Fr. Docum Mycol 28(111):47-67.

Consiglio G. 2000. Contributo alla conoscenza del Genere Pluteus II. Boll Circolo Micol G. Carini 40:15-36.

Corriol G, Moreau PA. 2007. Agaricus (Annularia) fenzlii redécouvert dans les Pyrénées. Notes sur le genre Chamaeota en Europe. Persoonia 19:233-250.

Courtecuisse R. 1991. Éléments pour un inventaire mycologique des environs de saut Pararé (Arataye) et de l'inselberg des Nouragues (Guyane française). V. Pluteaceae. (Pluteales, Basidiomycota). Cryptog Bot 23:136-152.

— Duhem B. 1994. Guide des champignons de France et d'Europe. Lausanne, Switzerland: Delachaux et Niestlé. 476 p.

Dennis RWG. 1953. Les Agaricales de L'Ile de la Trinité: Rhodosporae-Ochrosporae. Bull Soc Mycol Fr 69:145198.

Dermek A. 1987. Fungorum rariorum icones coloratae 16. Cramer. 23 p.

Drummond AJ, Ashton B, Cheung M, Heled J, Kearse M, Moir R, Stones-Havas S, Thierer T, Wilson A. 2009. Geneious 5.1.6. (Available from http://www.geneious. com)

Felsenstein J. 1985. Confidence limits on phylogenies: an approach using the bootstrap. Evolution 39:783-791, doi: $10.2307 / 2408678$

Gardes M, Bruns TD. 1993. ITS primers with enhanced specificity for basidiomycetes-application to the identification of mycorrhizae and rusts. Mol Ecol 2(2):113118, doi:10.1111/j.1365-294X.1993.tb00005.x

Gorovoj LF. 1990. Morfogenez plastinchatykh gribov (Mor- phogenesis of the gilled fungi). Kiev, Ukraine: Naukova dumka. 168 p.

Heilmann-Clausen J. 2008. Pluteus Fr. In: Knudsen H, Vesterholt J, eds. Funga nordica-agaricoid, boletoid and cyphelloid genera. Copenhagen: Nordsvamp. p 335-344.

Hibbett DS, Tsuneda A, Murakami S. 1994. The secotioid form of Lentinus tigrinus: genetics and development of a fungal morphological innovation. Am J Bot 81:466478, doi: $10.2307 / 2445497$

Homola RL. 1972. Section Celluloderma of the genus Pluteus in North America. Mycologia 64:1211-1247, doi: $10.2307 / 3757960$

Horak E. 1964. Fungi Austroamericani II. Pluteus Fr. Nova Hedwig 8:163-199, 20 pl.

Huelsenbeck JP, Larget B, Miller RE, Ronquist F. 2002. Potential applications and pitfalls of Bayesian inference of phylogeny. Syst Biol 51:673-688, doi:10.1080/ 10635150290102366

— phylogenetic trees. Bioinformatics 17:754-755, doi:10.1093/bioinformatics/17.8.754

Justo A, Vizzini A, Minnis AM, Menolli N, Capelari M, Rodríguez O, Malysheva E, Contu M, Ghignone S, Hibbett DS. 2011a. Phylogeny of the Pluteaceae (Agaricales, Basidiomycota): taxonomy and character Evolution. Fungal Biol 115:1-20, doi:10.1016/j.funbio.2010.09.012

_, Minnis AM, Ghignone S, Menolli N, Capelari M, Rodríguez O, Malysheva E, Contu M, Vizzini A. 2011b. Species recognition in Pluteus and Volvopluteus (Pluteaceae, Agaricales): morphology, geography and phylogeny. Mycol Prog, doi:10.1007/s11557-0100716-z

Kirk PM, Cannon PF, Minter DW, Stalpers JA. 2008. Dictionary of the Fungi. 10th ed. Wallingford, UK: CABI. 655 p.

Kornerup A, Wanscher JH. 1978. Methuen handbook of colour. 3rd ed. London: Eyre Methuen \& Co. Ltd.

Larkin MA, Blackshields G, Brown NP, Chenna R, McGettigan PA, McWilliam H, Valentin F, Wallace IM, Wilm A, Lopez R, Thompson JD, Gibson TJ, Higgins DG. 2007. Clustal W and Clustal X. Version 2.0. Bioinformatics 23: 2947-2948, doi:10.1093/bioinformatics/btm404

Malysheva EF, Malysheva VF, Krasilnikova AA. 2009. Morphological and molecular approaches to study the genus Pluteus Fr. Mikol Fitopatol 43:216-231.

— Morozova O, Zvyagina E. 2007. New records of the annulate Pluteus in European and Asian Russia. Acta Mycol 42:153-160.

Menolli Jr N, Asai T, Capelari M. 2010. Records and new species of Pluteus from Brazil based on morphological and molecular data. Mycology 1:130-153, doi:10.1080/ 21501203.2010.493531

Minnis AM, Sundberg WJ. 2009. Preliminary notes on Pluteus phylogeny. Nova Hedwig 89:303-319, doi:10.1127/0029-5035/2009/0089-0303

_ - 2010. Pluteus section Celluloderma in the USA. N Am Fungi 5:1-107, doi:10.2509/ naf2009.005.001 
- - Methven AS, Sipes SD, Nickrent DL. 2006. Annulate Pluteus species: a study of the genus Chamaeota in the United States. Mycotaxon 96:31-39.

Orton PD. 1986. British Fungus Flora Agarics and Boleti 4Pluteaceae: Pluteus \& Volvariella. Edinburgh: Royal Botanic Garden. 99 p.

Pegler DN. 1983. Agaric flora of the Lesser Antilles. London: Her Majesty's Stationery Office. 668 p. 27 pl.

Peintner U, Bougher NL, Castellano MA, Moncalvo JM, Moser MM, Trappe JM, Vilgalys R. 2001. Multiple origins of sequestrate fungi related to Cortinarius (Cortinariaceae). Am J Bot 88:2168-2179, doi: $10.2307 / 3558378$

Posada D. 2008. jModeltest: phylogenetic model averaging. Mol Biol Evol 25:1253-1256, doi:10.1093/molbev/ msn083

Reijnders AFM. 1963. Les problemes du developpement des carpophores des Agaricales et de quelques groupes voisins. The Hague, Netherlands: Junk. 412 p.

Rodríguez O, Galván-Corona A, Villalobos-Arámbula AR, Rodríguez A, Guzmán-Dávalos L. 2010. A new species of Pluteus (Pluteaceae, Agaricales) from Mexico. Mycotaxon 112:163-172, doi:10.5248/112.163

— — — - —argas G, Guzmán-Dávalos L. 2009. Pluteus horakianus, a new species from Mexico, based on morphological and molecular data. Sydowia 61:3952.

Singer R. 1956. Contributions towards a monograph of the genus Pluteus. Trans Br Mycol Soc 39:145-232, doi:10.1016/S0007-1536(56)80001-6 - 1958. Monographs of South American Basidiomycetes, especially those of the east slope of the Andes and Brazil 1. The genus Pluteus in South America. Lloydia 21:195-299.

- 1961. Monographs of South American Basidiomycetes, especially those of the east slope of the Andes and Brazil 4. Inocybe in Amazone region. Suppl. to pt. 1. Pluteus in South America. Sydowia 15:112-132.
1986. The Agaricales in modern taxonomy. 4th ed. Koenigstein, Germany: Koeltz Scientific Books. $981 \mathrm{p}$.

Swofford DL. 2002. PAUP*: phylogenetic analyses using parsimony (*and other methods). Version 4.0b10. Sunderland, Massachusetts: Sinauer Associates.

Tamura K, Dudley J, Nei M, Kumar S. 2007. MEGA 4: molecular evolutionary genetics analysis (MEGA). Version 4.0. Mol Biol Evol 24:1596-1599, doi:10.1093/molbev/msm092

Thiers B. 2010 [continuously updated]. Index Herbariorum: a global directory of public herbaria and associated staff. New York Botanical Garden's Virtual Herbarium. http:/ /sweetgum.nybg.org/ih/

Vellinga EC. 1990. Pluteus Fr. In: Bas C, Kuyper ThW, Noordeloos ME, Vellinga EC, eds. Flora Agaricina Neerlandica. Vol 2. Rotterdam, the Netherlands: A.A. Balkema. p 31-55.

_ Schreurs J. 1985. Notulae ad floram agaricinam neerlandicam VIII. Pluteus Fr. in West-Europe. Persoonia 12:337-373.

Vizzini A, Contu M, Musumeci E, Ercole E. 2011. A new taxon in the Infundibulicybe gibba complex (Basidiomycota, Agaricales, Tricholomataceae) from Sardinia (Italy). Mycologia 103:203-208, first published 31 Aug 2010 as doi:10.3852/10-137.

Walker LB. 1919. Development of Pluteus admirabilis and Tubaria furfuracea. Bot Gaz 68:1-21, doi:10.1086/ 332519

White TJ, Bruns TD, Lee S, Taylor J. 1990. Amplification and direct sequencing of fungal ribosomal RNA genes for phylogenetics. In: Innis MA, Gelfand DH, Snisky JJ, White TJ, eds. PCR protocols. London: Academic Press. p 315-322.

Yang ZL. 2007. Type studies on Chamaeota species described from China. Mycotaxon 100:279-287.

Ying JZ. 1995. New and noteworthy agarics from China I. New species of Chamaeota. Mycotaxon 54:303-307. 